\title{
Our Experiences in Conducting PBL Session at Universal College of Medical Sciences (UCMS) Bhairahawa Nepal
}

\author{
Piryani Rano Mal*1, Gautam Narayan², Nitasha Sharma ${ }^{3}$, Laxmi Shrestha ${ }^{4}$, Anita Shah ${ }^{5}$, Rubina \\ Shrestha ${ }^{6}$ Rita Khanal ${ }^{7}$ \\ ${ }^{1}$ Head of Department Internal Medicine and Chief Coordinator-Health Professions Training Committee, Universal College of Medical Sciences, Nepal \\ ${ }^{2}$ Department of Biochemistry, Coordinator PBL Implementation Committee \\ ${ }^{3}$ Department of Anatomy, Universal College of Medical Sciences, Nepal \\ ${ }^{4}$ Department of Pharmacology, Universal College of Medical Sciences, Nepal \\ ${ }^{5}$ Department of Pathology, Universal College of Medical Sciences, Nepal \\ ${ }^{6}$ Department of Community Medicine, Universal College of Medical Sciences, Nepal \\ ${ }^{7}$ Department of Microbiology, Universal College of Medical Sciences, Nepal
}

*Corresponding author: Piryani Rano Mal, Head of Department of Internal Medicine and Chief Coordinator-Health Professions Training Committee, Universal College of Medical Sciences, Nepal.

To Cite This Article: Piryani Rano Mal, et al. Our Experiences in Conducting PBL Session at Universal College of Medical Sciences (UCMS) Bhairahawa Nepal. Am J Biomed Sci \& Res. 2019 - 6(3). AJBSR.MS.ID.001024. DOI: 10.34297/AJBSR.2019.06.001024.

Received: 眥 October 28, 2019; Published: 眥 November 20, 2019

\begin{abstract}
Problem-based learning (PBL) is an educational strategy first introduced in McMaster University Canada fifty years back. In Nepal, it was first introduced in Tribhuvan University (TU) Institute of Medicine (IOM) early 1980s for sometimes. Subsequently, PBL implemented in B P Koirala Institute of Health Sciences (1998), Kathmandu University (KU) Medical School (2001), KU affiliated medical colleges (2011) and Patan Academy of Health Sciences (2010-2011). It has also been experimented in two medical colleges KIST Medical College (2011) and Chitwan Medical College (2015) affiliated to TU-IOM. The PBL as an educational strategy is just mentioned in TU-IOM MBBS curriculum (2008) and BDS curriculum (1999) but not practiced. Universal College of Medical Sciences (UCMS) Bhairahawa, Nepal established in 1998 is affiliated with TU-IOM. UCMS conducted one PBL session for first year MBBS / BDS for six-days June 16-21, 2019. Prior to implementation, one-day "Workshop on PBL for Tutors" was conducted for tutors for understanding PBL process and recognizing the role of tutor in conducting PBL. One PBL package was developed including scenario, 4-triggers and tutor guide. After workshop, implementation plan for session was developed.Students were oriented on first day for one-hour. Tutorials were conducted for two-hours (11.00-13.00) for first five-days with supervised self-directed learning (SDL) for two-hours in afternoon (14.00-16.00) with SDL continued at hostel. During tutorials students encountered patient's problem comprised of four-triggers; they identified cues, established learning needs and developed learning objectives followed by discussion. Seminar was arranged on last day for four-hours. Feedback from students was obtained on structured questionnaire and students received feedback individually from respective tutor in afternoon of last day. Students presentations in seminar were orderly, logical, and delivered proficiently. Tutors communicated that students were motivated, satisfied, participated actively, they acquired optimal knowledge and their communication, analytical and problem-solving skills enhanced. Students feedback was positive and constructive.
\end{abstract}

Keywords: Educational strategy; Experiences; Feedback; Problem-based learning; PBL package; Tutor

\section{Problem-Based Learning (PBL):}

Problem-based learning (PBL) is one of the innovative educational strategies. It has been implemented for over last half century since it was first adopted by Mc Master University in Canada in 1969. It has now been part of curriculum of many medical schools all over the world including Asia [1,2]. PBL is a student-centered and problem-solving instructional strategy or approach where the learners first encounter a problem, followed by a systematic enquiry process and self-directed leaning [3-5]. 


\section{Undergraduate Curriculum of Tribhuvan University Institute of Medicine (TU-IOM)}

TU-IOM runs its medical school named Maharajganj Medical Campus and seven private medical colleges and seven dental colleges are affiliated with it. All medical colleges have been implementing undergraduate curriculum for medicine (MBBS) revised in 2008 and all dental colleges have been implementing undergraduate curriculum for dentistry (BDS) revised in 1999. The undergraduate MBBS curriculum is students centered, information oriented, uniform, systematic, community oriented and horizontally integrated while undergraduate BDS curriculum is students centered, information oriented, uniform, systematic, hospital based and horizontally integrated. The problem-based learning strategy is just mentioned in both curriculums but not practiced [6,7]. TUIOM is in process of revising both undergraduate medicine and dentistry curriculums.

\section{PBL implementation in medical schools in Nepal}

PBL was first introduced in Maharajganj Medical Campus of Tribhuvan University Institute of Medicine Kathmandu in Nepal in 1978-1980 as a teaching learning strategy [8,9]. It was implemented for sometimes. B P Koirala Institute of Health Sciences (BPKIHS), Dharan Nepal introduced PBL in 1998 [8]. Kathmandu University (KU) started implementation of PBL in its school (Kathmandu University Medical School-KUMS) at Dulikhel in 2001; later, KU introduced PBL in its affiliated medical colleges (2011) [8]. The curriculum of Patan Academy of Health Sciences (PAHS), Lalitpur is PBL based started in 2010-2011 [9,10]. PBL has been fractionally implemented in KIST Medical College Lalitpur and Chitwan Medical College Bharatpur since 2011 and 2015 respectively [9].

\section{Universal College of Medical Sciences (UCMS)}

Universal College of Medical Sciences (UCMS) Bhairahawa Nepal established in 1998 is affiliated with Tribhuvan University Institute of Medicine (TU-IOM). It runs undergraduate and postgraduate courses in medicine, dentistry, nursing and allied sciences [11]. It implements undergraduate curriculum for medicine (MBBS) revised in 2008 and undergraduate curriculum for dentistry (BDS) revised in $1999[6,7]$.

\section{Health Professions Training Committee of UCMS}

With the purpose to strengthen the capacity and competence of health professionals of UCMS, Health Professions Training Committee (HPTC) was constituted on January 09, 2019. The objectives of HPTC are: 1) to train the health professionals of UCMS in various aspects of health professions education, 2) to utilize the talent of health professionals of UCMS for reinforcement of quality education and quality care, and 3) to enhance the capability and aptitude of students. Besides other trainings, HPTC organized 6-days "Teachers Training Workshop" in March 11-16, 2019. "Problem-based learning related sessions" were among the five main groups of sessions conducted in the training; other groups of session were curriculum related sessions, teaching/learning methods related sessions, microteaching related sessions and assessment related session. Later, one of the members of HPTC was sent to TU-IOM for participation in 3-days PBL training held on May 8-10, 2019.

\section{PBL Implementation Committee of UCMS}

The PBL implementation committee was formed under the umbrella of HPTC on May 14, 2019. A coordinator and nine members were selected. The committee was assigned to arrange one day workshop for members of PBL implementation committee on "how to implement PBL in UCMS", and make an implementation plan for organizing one PBL session each for first year MBBS/BDS and 2nd year MBBS/BDS during this academic year in coordination with chief coordinator of HPTC.

\section{PBL workshop for Tutors}

A one-day "Workshop on PBL for Tutors" was conducted in June 04, 2019 at UCMS, Bhairahawa, Nepal by lead author and second author as resource persons. The main objective of workshop was to prepare faculty members for implementation of PBL in UCMS. The specific objectives were to understand the PBL process, recognize the role of tutor in conducting PBL session, design and develop PBL packages including formulation of scenario, triggers, tutor guide and orient students on PBL process. During workshop one PBL package was developed which include PBL scenario, 4-triggers and tutor guide for conducting PBL session for first year MBBS/BDS.

\section{Implementation of PBL Session at UCMS}

\section{Before PBL session}

After workshop, plan for implementation of one PBL session for students of first year MBBS and BDS was developed. The date for session was scheduled in third week of June 16- 21, 2019 and notified a week prior to implementation. Orientation for students was planned for first day for one hour 10.00-11.00am. Tutorials were timetabled for two hours 11.00-13.00 hours for first five days June (16-20,2019) with supervised self-directed learning (SDL) for 2 hours in the afternoon 14.00-16.00 hours with SDL continued at hostel. The seminar was scheduled on last day of session June 21, 2019 (see Table 1). Students (No140) of first year MBBS/BDS were divided into 10 groups randomly, notified and informed to the students. Each group comprised of 14 students, 10 from MBBS and 4 from BDS. Places for 10 tutorial rooms with adequate seating arrangement were identified by PBL team and informed to the students. Logistics like flip board, white board etc. and stationary like flip chart papers, markers etc. were arranged by PBL coordinator. Chief coordinator HPTC accessed the "Tutorial Evaluation Report for students" and "Feedback Questionnaire for feedback from the students" from google; required numbers of photocopies were obtained. Daily attendance sheets were prepared by PBL coordinator and print out was taken (Table 1). 


\begin{tabular}{|c|c|c|c|c|c|c|}
\hline Time/Day & Day One & Day Two & Day Three & Day Four & Day Five & Day Six \\
\hline $09.00-10.00$ & Assemble in hall & $\begin{array}{l}\text { Self-directed } \\
\text { Learning (SDL) }\end{array}$ & $\begin{array}{l}\text { Self-directed } \\
\text { Learning (SDL) }\end{array}$ & $\begin{array}{c}\text { Self-directed } \\
\text { Learning (SDL) }\end{array}$ & $\begin{array}{c}\text { Self-directed } \\
\text { Learning (SDL) }\end{array}$ & \multirow{5}{*}{$\begin{array}{l}\text { Seminar } \\
\text { Group-wise Presentation } \\
\text { by students with } \\
\text { response to questions } \\
\text { raised by the students } \\
\text { of other groups by } \\
\text { presenting group }\end{array}$} \\
\hline $10.00-11.00$ & $\begin{array}{l}\text { Orientation for } \\
\text { students }\end{array}$ & & & & & \\
\hline $11.00-13.00$ & Tutorial & Tutorial & Tutorial & Tutorial & Tutorial & \\
\hline First Hour & $\begin{array}{l}\text { Introduction } \\
\text { of students } \\
\text { Ground Rules \& } \\
\text { Briefing }\end{array}$ & $\begin{array}{c}\text { Discussion on } \\
\text { learning objectives } \\
\text { of trigger } 1\end{array}$ & $\begin{array}{c}\text { Discussion on } \\
\text { learning objectives } \\
\text { of trigger } 2\end{array}$ & $\begin{array}{c}\text { Discussion on } \\
\text { learning objectives } \\
\text { of trigger } 3\end{array}$ & $\begin{array}{l}\text { Discussion on } \\
\text { learning objectives } \\
\text { of trigger } 4\end{array}$ & \\
\hline Second Hour & $\begin{array}{c}\text { Introduction } \\
\text { of trigger } 1 \\
\text { Identify cues find } \\
\text { out learning needs } \\
\text { Develop learning } \\
\text { objectives }\end{array}$ & $\begin{array}{c}\text { Introduction } \\
\text { of trigger } 2 \\
\text { Identify cues find } \\
\text { out learning needs } \\
\text { Develop learning } \\
\text { objectives }\end{array}$ & $\begin{array}{c}\text { Introduction } \\
\text { of trigger } 3 \\
\text { Identify cues find } \\
\text { out learning needs } \\
\text { Develop learning } \\
\text { objectives }\end{array}$ & $\begin{array}{c}\text { Introduction } \\
\text { of trigger } 4 \\
\text { Identify cues find } \\
\text { out learning needs } \\
\text { Develop learning } \\
\text { objectives }\end{array}$ & $\begin{array}{l}\text { Briefing about } \\
\text { seminar } \\
\text { Facilitation } \\
\text { for seminar } \\
\text { presentation }\end{array}$ & \\
\hline $13.00-14.00$ & Lunch & Lunch & Lunch & Lunch & Lunch & Lunch \\
\hline \multirow{2}{*}{$14.00-16.00$} & \multirow{2}{*}{ Supervised SDL } & \multirow{2}{*}{ Supervised SDL } & \multirow{2}{*}{ Supervised SDL } & \multirow{2}{*}{ Supervised SDL } & \multirow{2}{*}{$\begin{array}{l}\text { Supervised } \\
\text { Preparation of } \\
\text { presentation for } \\
\text { seminar }\end{array}$} & $\begin{array}{l}\text { Feedback to individual } \\
\text { student by respective } \\
\text { tutor }\end{array}$ \\
\hline & & & & & & $\begin{array}{l}\text { Written Feedback } \\
\text { by students on } \\
\text { questionnaire }\end{array}$ \\
\hline After 16.00 & $\begin{array}{c}\text { SDL continue at } \\
\text { hostel }\end{array}$ & $\begin{array}{l}\text { SDL continue at } \\
\text { hostel }\end{array}$ & $\begin{array}{l}\text { SDL continue at } \\
\text { hostel }\end{array}$ & $\begin{array}{l}\text { SDL continue at } \\
\text { hostel }\end{array}$ & $\begin{array}{l}\text { SDL continue at } \\
\text { hostel }\end{array}$ & \\
\hline
\end{tabular}

\section{During PBL week}

Day one: orientation session: Students were oriented on first day in one-hour interactive session covering what is PBL, why PBL, what is process of PBL, what is scenario, what is trigger, what are cues, learning needs, and learning objectives, what is role of tutor, how students have to participate in tutorial, what is self-directed learning, what are learning resources, how learning resources can be used, about small group work discussion etc.

Day one: tutorial one: PBL coordinator handed over the tutorial guide to individual group tutor. Tutor of each group introduced himself/herself to students and subsequently students introduced each other. Then tutor shared norms of tutorial with students. Students selected one leader and one scriber among themselves. Students then themselves articulated ground rules to be followed during tutorial, put on flip chart and displayed on prominent place within tutorial room to be seen by everyone as a reminder. Then tutor shared trigger 1; students after interaction identified clues, developed learning needs and learning objectives. Tutor facilitated their learning and kept them on track. Students dispersed for lunch at 13.00-hour and assembled again at 14.00-hour for SDL which was supervised by respective tutor. Respective tutor took attendance twice in day.

Observation of tutorial: HPTC chief coordinator and PBL coordinator observed the tutorial process.
PBL implementation committee meet: Members briefed to HPTC Chief coordinator about proceedings of days' activities.

Day two: tutorial two: Students reached the tutorial room on time and did discussion on identified learning objectives of trigger one for one hour. After discussion new scriber and leader was selected. Then tutor shared trigger 2; students after interaction identified clues, developed learning needs and learning objectives. Tutor facilitated their learning and kept them on track. Students dispersed for lunch at 13.00-hour and assembled again at14.00hour for SDL which was supervised by respective tutor. Respective tutor took attendance twice in day.

Observation of tutorial: HPTC chief coordinator and PBL coordinator observed the tutorial process.

PBL implementation committee meet: Members briefed to HPTC Chief coordinator about proceedings of days activities.

Day three: tutorial three: Students assembled in the tutorial room sharp on time and completed discussion on identified learning objectives of trigger two for one hour. After discussion new scriber and leader was selected. Then tutor shared trigger 3; students after interaction identified clues, developed learning needs and learning objectives. Tutor facilitated their learning and kept them on track. Students dispersed for lunch at 13.00-hour and gathered again at14.00-hour for SDL which was supervised by respective tutor. Respective tutor took attendance twice in day. 
Observation of tutorial: HPTC chief coordinator and PBL coordinator observed the tutorial process.

PBL implementation committee meet: Members briefed to HPTC Chief coordinator about proceedings of days activities.

Day four: tutorial four: Students arrived in the tutorial room on time and completed discussion on identified learning objectives of trigger three for one hour. After discussion new scriber and leader was selected. Then tutor shared trigger 4; students after interaction identified clues, developed learning needs and learning objectives. Tutor facilitated their learning and kept them on track. Students dispersed for lunch at 13.00-hour and assembled again at14.00hour for SDL which was supervised by respective tutor. Respective tutor took attendance twice in day.

Observation of tutorial: HPTC chief coordinator and PBL coordinator observed the tutorial process.

PBL implementation committee meet: Members briefed to HPTC Chief coordinator about proceedings of days activities.

Day five: tutorial five: Students arrived in the tutorial room on time and finished discussion on identified learning objectives of trigger three for one hour. After discussion new scriber and leader was selected. Then PBL coordinator called leader of each group and randomly distributed the topic for presentation in seminar scheduled on last day. Tutor facilitated their learning, kept them on track and guided for preparation of presentation. Students dispersed for lunch at 13.00-hour and assembled again 14.00-hour for preparation of presentation. Respective tutor took attendance twice in day.
Observation of tutorial: HPTC chief coordinator and PBL coordinator observed the tutorial process.

PBL implementation committee meet: Members briefed to HPTC Chief coordinator about proceedings of days activities.

Day six: seminar: Ten groups presented topic based on leaning objectives in sequence. Each presentation was of 12 minutes followed by three questions from other groups to be responded by presenting group within 3-5 minutes. PBL implementation committee members facilitated students during seminar. Students dispersed for lunch at 13.00-hour and assembled again at 14.00-hour for feedback session. Students received feedback individually from respective tutor about tutorial evaluation. The tutorial evaluation done by tutor for communication skills, about knowledge, problem solving and analytical thinking skills and personal and interpersonal development. Students consented to provide feedback on PBL session. For obtaining feedback from the students structured questionnaire was used. The feedback was on overall satisfaction of problem-based learning by students, the satisfaction with self-motivated learning and small group activity, the satisfaction with tutor and composition of PBL package, students' perceptions as difficult process for performing problemsolving and the advantage and disadvantage of problem-based learning.

PBL implementation committee meet: Members briefed to HPTC Chief coordinator about proceedings of days activities. Respective tutor took attendance twice in day. Figures 1-3 show cues, leaning need and learning objectives developed by Student.
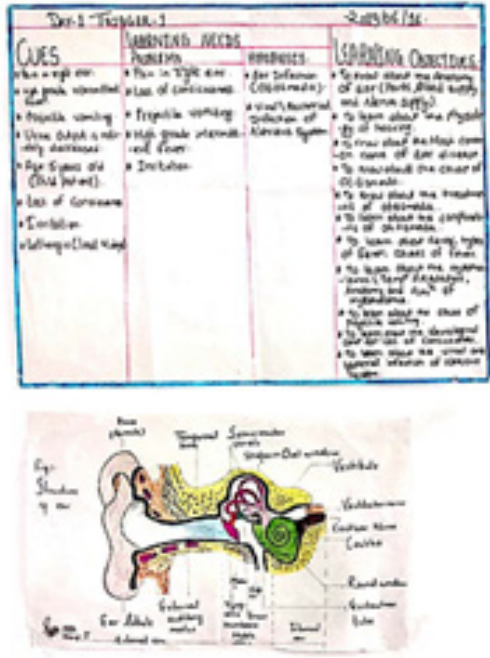

Scanned with CamScanner

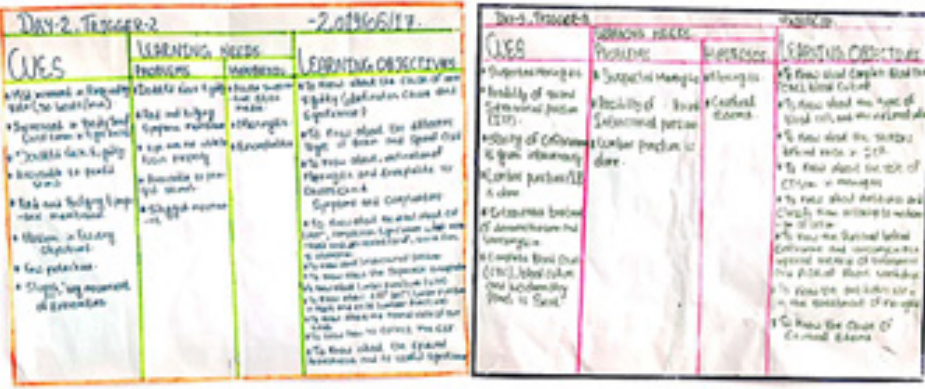

Figure 1

Cues, Leaning Objectives and learning needs by one group of students in PBL Session conducted for first year MBBS/ BDS at Universal College of Medical Sciences Bharaihawa Nepal

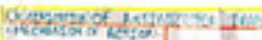

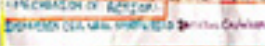

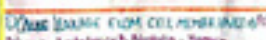

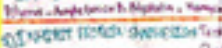
950

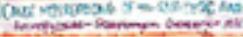

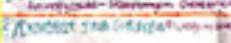

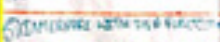

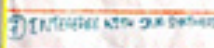

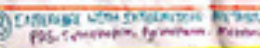

Figure 1 


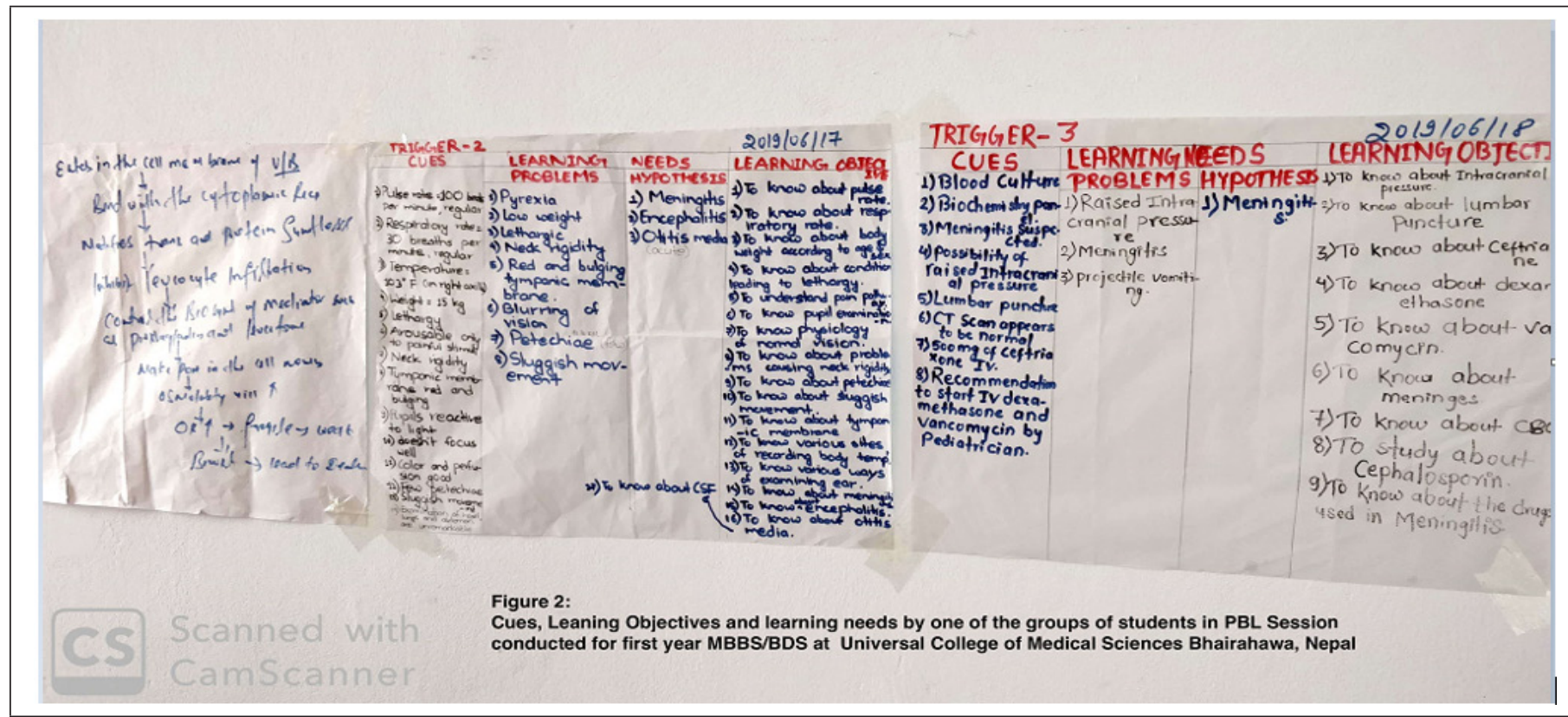

Figure 2

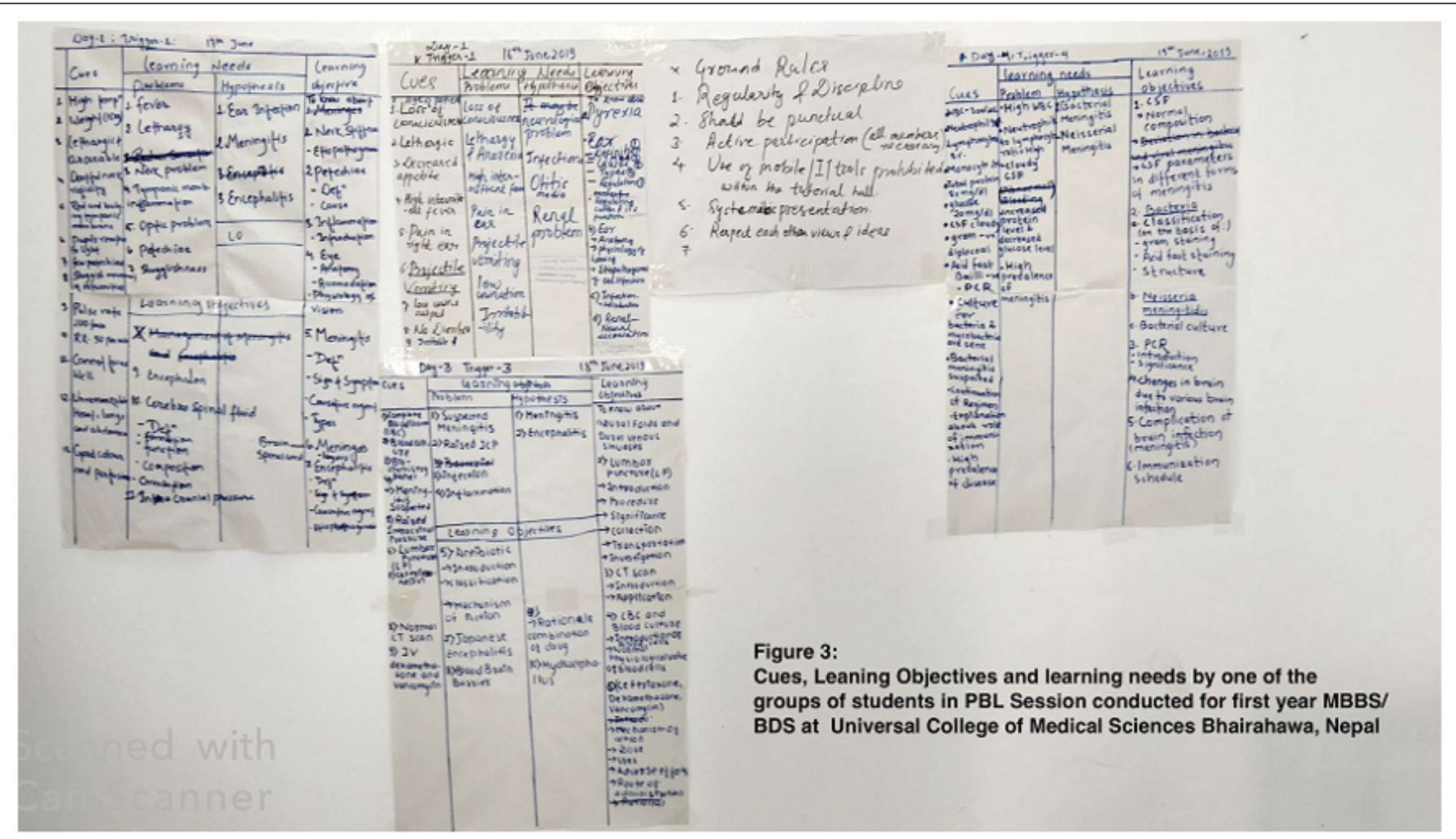

Figure 3

\section{After PBL Session}

PBL implementation committee met and discussed about what went well and what were the areas for improvement. Tutors communicated that students were motivated, satisfied, participated actively in small group activity, their communication skills improved, they acquired optimal knowledge and their analytical and problem-solving capacity enhanced. Students presentations in seminar were very systematic, logical, well organized and delivered skillfully. HPTC chief coordinator and PBL coordinator observed the tutorial process daily and satisfied with PBL process, facilitation by the tutor and participation of students. There were some deficiencies in logistics. The student's feedback was very positive and constructive. 


\section{Conclusion}

Overall PBL session was well planned, organized, conducted and executed. The PBL process and tutorial proceedings were satisfactorily facilitated by tutors and reasonably managed by PBL coordinator and HPTC chief coordinator. Students participations were commendable. They were gratified, updated their communication skills, learnt about self-directed learning process, small group activity process, use of learning resources, analytical skills, problem solving skills and interpersonal development.

\section{References}

1. Sahu PK, Sa B (2015) Tutor's Role in Problem-based learning: Minimum Interference with Maximum Responsibility. Utopia of Global Education $1(2): 1-9$

2. Alshiek MAH, Elbashir AM, Abdelrahman AM, Alsareii SA (2017) Tutors' role and responsibility in (PBL): pros and Cons of subject expert and tutorial process expert literature overview. IERJ 3(4): 42-44.

3. Sa B, Ezenwaka C, Singh K, Vuma S, Majumder MMA (2019) Tutor assessment of PBL process: does tutor variability affects objectivity and reliability? BMC Medical Education 19(76).

4. Anita DK, Pathak R, Chai JW, Noor H, Rohaini M, et al. (2012) Early Introduction of Problem-Based Learning into the Integrated Curriculum of a Newly Established Medical School in Malaysia. J Community Med Health Educ 2: 189.

5. El-Aziz El Naggar MAA, Maklady FAH, Hamam AM, Omar AS (2013) Effectiveness of Implementing a Tutor Training Workshop for Problem Based Learning Class Tutors at the Faculty of Medicine, Suez Canal University. Intel Prop Rights 1(1): 104.

6. Curriculum for Bachelor of Medicine \& Bachelor of Surgery Tribhuvan University Institute of Medicine. Revised in 2008 published by Medical Education Department, Institute of Medicine, Nepal.

7. Curriculum for Bachelor of Dentistry, Tribhuvan University Institute of Medicine. Revised in 1999 published by Medical Education Department, Institute of Medicine, Nepal.

8. Pradhan B, Ranjit E, Ghimire MR, Dixit H (2012) History of Problem Based Learning in Nepal and Experience at Kathmandu Medical College. Journal of Kathmandu Medical College 1(1): 37-44.

9. Yadav RL, Piryani RM, Deo GP, Shah DK, Yadav LK, et al. (2018) Attitude and perception of undergraduate medical students toward the problembased learning in Chitwan Medical College, Nepal. Advances in Medical Education and Practice 9: 317-322.

10. Upadhyay SK, Bhandary S, Ghimire SR, Maharjan BR, Shrestha I, et al. (2015) Preparing faculty for problem-based learning curriculum at Patan Academy of Health Sciences. Journal of Patan Academy of Health Sciences 2(1): 22-24.

11. Overview UCMS. www.ucms.com.np. 